NISTIR 89-3917

\title{
IMPROVED LOW-LEVEL \\ SILICON-AVALANCHE-PHOTODIODE \\ TRANSFER STANDARDS AT \\ 1.064 MICROMETERS
}

A.L. Rasmussen

P.A. Simpson

A.A. Sanders

National Institute of Standards and Technology

U.S. Department of Commerce

Boulder, Colorado 80303-3328

August 1989

$-Q C$

100

.456

89-3917

1989

C. 2 


\section{NATIONAL INSTITUTE OF STANDARDS \& TECHNOLOGY Research Information Center \\ Gaithersburg, MD 20899}

\section{DATE DUE}

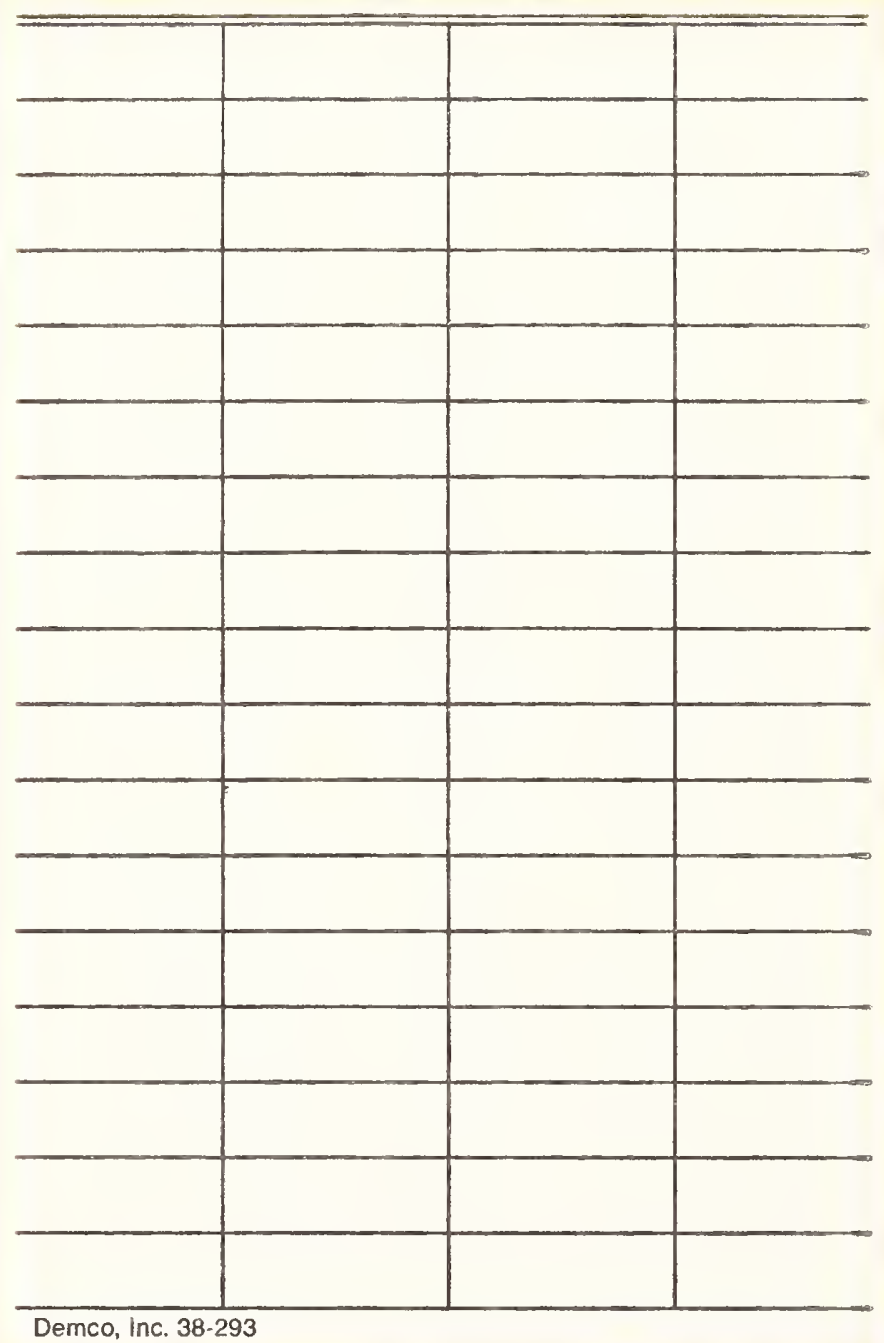




\section{IMPROVED LOW-LEVEL SILICON-AVALANCHE-PHOTODIODE TRANSFER STANDARDS AT 1.064 MICROMETERS}

\section{A.L. Rasmussen}

P.A. Simpson A.A. Sanders

Electromagnetic Technology Division

Center for Electronics and Electrical Engineering National Engineering Laboratory

National Institute of Standards and Technology

Boulder, Colorado 80303-3328

August 1989

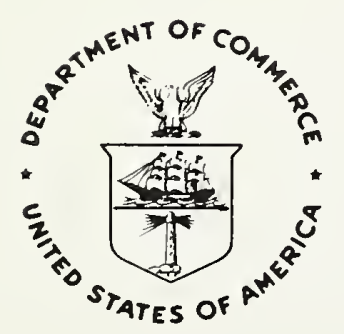





\section{CONTENTS}

ABSTRACT $\ldots \ldots \ldots \ldots \ldots \ldots \ldots \ldots \ldots \ldots \ldots \ldots \ldots \ldots \ldots \ldots \ldots \ldots \ldots \ldots \ldots . \ldots \ldots \ldots$

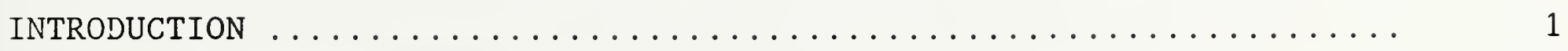

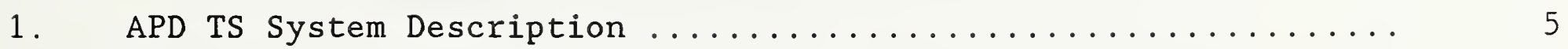

2. Warning When Using the APD TS System ................ 7

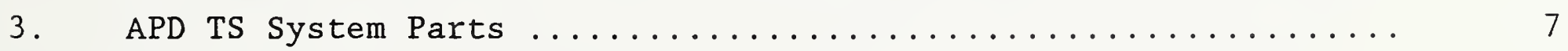

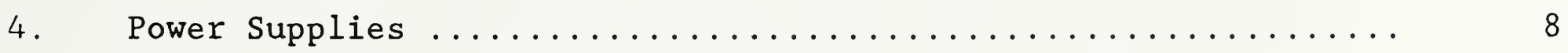

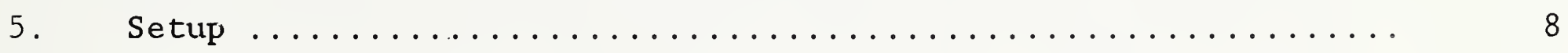

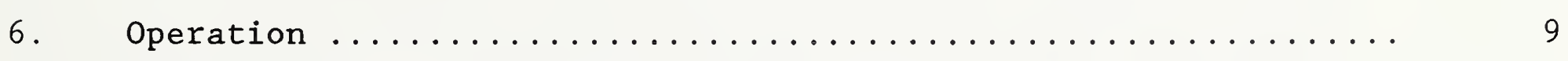

7. Making APD TS Measurements ....................... 10

8. Shut-Down .............................. 10

9. APD TS Equipment ......................... 10

10. Calibration Procedures ........................... 11

11. Acknowledgments .............................. 14

12. References ................................ 14 



\title{
Improved Low-Level Silicon-Avalanche-Photodiode Transfer Standards at 1.064 Micrometers.
}

\author{
A.L. Rasmussen, P.A. Simpson, and A.A. Sanders \\ Electromagnetic Technology Division \\ National Institute of Standards and Technology \\ Boulder, Colorado 80303
}

\begin{abstract}
Three silicon-avalanche-photodiode (APD) transfer standards were calibrated from $\sim 10^{-8}$ to $\sim 10^{-5} \mathrm{~W} / \mathrm{cm}^{2}$ peak power density at approximately $10 \%$ uncertainty. These calibrations are for $1.064 \mu \mathrm{m}$ wavelength pulses of 10 to 100 ns duration. For this calibration, an acousto-optically modulated laser beam generated alternately equal levels of pulsed power and $\mathrm{cw}$ power into a low-level beam splitter. The cw power measured by a transfer standard in the transmitted beam of the splitter was used to determine the pulsed power into the APD transfer standard in one of the low-level reflected beams of the splitter. The APD detector had about a 1 $\mathrm{cm}^{2}$ aperture and a $3.8 \mathrm{~cm}$ focal length lens in front of it. Lens, window, and detector surfaces had narrow-band antireflection coatings. The commercial detector package is a temperature compensated, infrared-enhanced APD preamplifier module. To increase the sensitivity, one or two $20 \mathrm{~dB}, 500 \mathrm{MHz}$ bandwidth amplifiers followed the preamplifier. With very low pulsed power, a $30 \mathrm{MHz}$ low-pass filter with Gaussian roll-off was attached to the amplifier output to reduce the noise. A transient digitizer recorded the impulse responses of the APD detectors at $1.064 \mu \mathrm{m}$. These data were read into computer programs that convolved the unit-area impulse response with unit-height Gaussian pulses. From these data, correction factors of the pulse peak for observed pulse durations from 10 to 100 ns were determined. Instructions, calibrations, error budgets, and system descriptions are included.
\end{abstract}

Key words: detector impulse response; laser pulse detectors; laser pulse standards; low-level pulse detectors; pulse power measurements; YAG laser pulse calibrations

\section{INTRODUCTION}

Laser designator and range-finder applications have prompted the development of low-level transfer standards at the National Institute of Standards and Technology. The three silicon-avalanche-photodiode transfer standards (APD TS) described in this report have improved sensitivity, stability and accuracy over previous APD transfer standards [1],[2],[3]. Table A, Characteristics of Silicon-Avalanche-Photodiode Transfer Standards (APD TS), and the section that follows give details about these detectors. 


\section{DISCLAIMER}

Certain commercial equipment, instruments, and materials are identified in this publication in order to explain the experimental procedure adequately. Such identification in no way implies approval, recommendation, or endorsement by the National Institute of Standards and Technology, nor does it imply that the equipment, instruments, or materials identified are necessarily the best available for the purpose. 
TABLE A. Characteristics of Silicon-Avalanche-Photodiode Transfer Standards (APD TS)

\section{Parameter \\ Noise \\ Range \\ Responsivity \\ Collector lens}

Detector

$20 \mathrm{~dB}$ and $40 \mathrm{~dB}$

(two $20 \mathrm{~dB}$ units)

amplifiers

(follow preamplifier)

$30 \mathrm{MHz}$ filter

(follows amplifiers

when used)
Characteristics

$\sim 4 \times 10^{-9} \mathrm{~W} / \mathrm{cm}^{2}$

$\sim 10^{-8}$ to $\sim 10^{-5} \mathrm{~W} / \mathrm{cm}^{2}$

1. Manufacturer's temperature coefficient of responsivity $\sim 0.18 /{ }^{\circ} \mathrm{C}$ using temperature compensation circuit.

2. Temperature controller $35^{\circ} \mathrm{C} \pm \sim 0.25^{\circ} \mathrm{C}$ used when environment is severe.

1. Narrow-band $1.064 \mu \mathrm{m}$ antireflection coating on surfaces.

2. Planoconvex lens with $\mathrm{FL} 3.8 \mathrm{~cm}$ and OD $2.5 \mathrm{~cm}$.

3. Aperture in front of lens approximately $1 \mathrm{~cm}^{2}$.

4. Lens and detector separated so that collimated beam is a little defocused at the detector. Lens position is read on the scale adjacent to the lens holder, and it is held with a locking nut.

1. Narrow-band $1.064 \mu \mathrm{m}$ antireflection coated window and detector.

2. APD-preamplifier module.

3. Dimples in surface of detector to increase internal reflection of beam.

4. Detector uniformity eliminates need for diffuser.

5. Diameter of detector $0.3 \mathrm{~cm}$.

1. $-3 \mathrm{~dB}$ BW $500 \mathrm{MHz}$

2. $20 \mathrm{~dB}$ gain (noninverting) DC to $300 \mathrm{MHz}$

3. Input and output impedance 50

4. Dynamic range $72 \mathrm{~dB}$.

5. Rise and fall times 0.6 to $0.75 \mathrm{~ns}$.

6. Equivalent input noise, $10 \mathrm{~Hz}$ to $500 \mathrm{MHz}$ $\mathrm{BW}, 20 \mu \mathrm{V}$.

7. Second and third harmonic distortion $-60 \mathrm{dBc}(\max -50 \mathrm{dBc})$

1. Gaussian roll-off

2. Lowpass

3. $3 \mathrm{~dB}$ cut-off frequency, $30 \mathrm{MHz}$. 



\section{APD TS System Description.}

These transfer standards will measure $\sim 10^{-8}$ to $10^{-5} \mathrm{~W} / \mathrm{cm}^{2}$ peak power density of $\sim 10$ to $100 \mathrm{~ns}$ duration pulses at $1.064 \mu \mathrm{m}$ wavelength. See figure 1 .

The detector package is a specially ordered commercial unit. An antireflection coated lens and fixed aperture are mounted in front of the $3 \mathrm{~mm}$ diameter detector, which has an antireflection coated window. The complete unit is housed in a black box with attached legs and platform.

Power supplies are provided for the detector, preamplifier, amplifiers, and temperature controller. Temperature compensation in the detector package maintains the responsivity with negligible change over a broad temperature range. The temperature controller was designed to maintain the detector at a given temperature when needed.

The detector unit is a temperature compensated silicon-avalanchephotodiode preamplifier module. The detector is IR-enhanced and has an array of dimples on its surface. These dimples and an antireflection coating on the detector surface increase the signal absorption and responsivity. Because of the dimples the responsivity will show nonuniformity when the surface is scanned with a very small beam. Using a 0.3-0.4 cm diameter beam that was focused to a small spot, we calibrated the detector at the center of the surface. It 
was also calibrated at seven mathematically selected locations ${ }^{1}$ on the surface to determine the uniformity of the responsivity with the given beam. APD 721 and APD 723 were rotated $45^{\circ}$ and calibrated at seven locations again.

From these data the center calibration was given a correction factor and uncertainty for the uniformity.

When a $\sim 10 \mathrm{~cm}$ diameter, stable, uniform, collimated LED beam was directed into the detector with $0.5 \mathrm{~cm}^{2}$ and $1 \mathrm{~cm}^{2}$ apertures, the detector output was proportional to the area of these apertures. The responsivity of the detector was uniform to these larger beams.

To increase the sensitivity of detection, one or two amplifiers are attached to the preamplifier output. These may be followed by a $30 \mathrm{MHz}$ low-pass filter with Gaussian roll-off to reduce noise and to measure $\sim 10^{-8} \mathrm{w} / \mathrm{cm}^{2}$ peak power density of $20 \mathrm{~ns}$ duration pulses. Since the filter lengthens the impulse response time of the system, the correction factor for the peak voltage changes accordingly.

At $1.064 \mu \mathrm{m}$ correction factors for peak voltage at the observed pulse duration are given for $0 \mathrm{~dB}, 20 \mathrm{~dB}$ (with and without the $30 \mathrm{MHz}$ lowpass filter), and $40 \mathrm{~dB}$ (with the $30 \mathrm{MHz}$ low-pass filter).

${ }^{1}$ Handbook of Mathematical Functions, U.S. Department of Commerce, National Bureau of Standards, AMS 55. Edited by M. Abramowitz and Irene A. Stegun, June 1964, p 892. Weighted average of seven points in circular area with $h=0.4 \mathrm{~cm}$ was the same as the average of the seven values. Rotating the detectors $45^{\circ}$ and taking seven more points yielded similar averages. 


\section{Warning When Using the APD TS System}

a. Stay within the power and voltage ranges in the table of the APD TS system.

b. Do not exceed these limits for you can burn out components in the APD TS system and cost considerable expense and time to repair, replace, and recalibrate.

c. Do not disassemble the APD TS for you can ruin its calibration.

d. Operate the APD TS in a darkened room to prevent instrument damage and erroneous measurements.

e. Observe input/output connections of amplifier(s) and the $30 \mathrm{MHz}$ low-pass filter.

f. Stay within the ranges given for the amplifiers. You can damage them if you exceed these limits. Also, just slightly exceeding these limits can introduce subtle errors.

\section{APD TS System Parts.}

a. APD TS with built in lens and aperture.

b. Alignment mirror and iris.

c. Two lens mount sleeves.

d. Detector bias power supply.

e. Preamplifier bias power supply.

f. Temperature controller power supply.

g. Temperature measuring equipment (digital voltmeter provided by user).

h. Ungrounded precision voltmeter (provided by user).

i. Two $20 \mathrm{~dB}$ amplifiers with power supply attached.

j. $30 \mathrm{MHz}$ filter.

k. Cables. 


\section{Power Supplies}

a. Preamplifier bias power supply, $\pm 9.0 \mathrm{~V}$.

b. Detector bias power supply, $+550.0 \mathrm{~V}$. Turn on or off by gradually increasing or decreasing voltage.

c. Temperature controller power supply, $+15 \mathrm{~V}$ (not generally used because temperature compensator circuit of the detector maintains a calibration that changes negligibly over a broad temperature range).

\section{Setup}

a. Do not connect the temperature controller power supply and temperature meter to the detector unless temperature control is needed.

b. If you need temperature control, connect the temperature controller to the detector, and a digital ohmmeter (operating temperature reading about $3.5 \mathrm{k} \Omega$ ) to the temperature meter terminal of the detector.

c. Attach detector bias power supply to the detector $+550.0 \mathrm{~V}$ terminal and to an ungrounded precision voltmeter (furnished by user).

d. Attach preamplifier power supply to the appropriate terminal of the detector using the flexible grey cable.

e. Attach output terminal of the detector to a 7A24 oscilloscope plug-in of a 7904 oscilloscope or equivalent for $0 \mathrm{~dB}$ gain measurements or to the $20 \mathrm{~dB}$ amplifier for $20 \mathrm{~dB}$ gain or the two $20 \mathrm{~dB}$ amplifiers in series for $40 \mathrm{~dB}$ gain. Attach amplifiers in order of serial numbers given in calibration tables $1-3$, see footnote $\dagger$. 
f. For lower noise attach the $30 \mathrm{MHz}$ low-pass filter to the output of the amplifier(s).

g. For wider bandwidth attach the $20 \mathrm{~dB}$ amplifier with serial number given in the calibration tables $1-3$, see footnote $\dagger$, without the $30 \mathrm{MHz}$ low-pass filter.

h. Attach the amplifier or $30 \mathrm{MHz}$ low-pass filter output to the oscilloscope plug-in.

i. Observe input/output connections of amplifier(s) and the $30 \mathrm{MHz}$ low-pass filter.

\section{Operation}

a. Turn on preamplifier power supply.

b. Turn on detector bias power supply, gradually increasing voltage until it reads exactly the operating voltage. Return the voltage to zero in a like manner when shutting off equipment.

c. Turn on amplifiers being used, and disconnect and turn them off when changing or shutting off equipment.

d. Remove the alignment mirror from the detector.

e. Blow dust off the APD collector with a squeeze-type air blower ONLY (other types such as those in spray cans may spray liquid and damage the surface).

f. Reattach the alignment mirror and attach the iris.

g. Align the APD TS in a visible or $1.064 \mu \mathrm{m}$ beam with the beam returning on itself, or

h. Using a collimated beam, align the APD TS without the alignment mirror and iris by positioning it for maximum pulse height at a gain and range given in the calibration table. 


\section{Making APD TS Measurements}

a. Set a baseline of two divisions and a pulse height of three to five divisions.

b. Refer to tables 1, 2, 3, and 4 for gain, calibration, range, and uncertainty.

c. Read the peak voltage and the observed pulse duration (FDHM) .

d. Find the corrected peak voltage by multiplying the observed value by the correction factor in figures 2 through 13.

e. Divide the corrected peak voltage by the calibration in column 1 of tables 1, 2, or 3 to get the power density $\left(\mathrm{W} / \mathrm{cm}^{2}\right)$.

f. Acquire enough data for significant statistical information.

\section{Shut-Down}

a. Disconnect and turn off the amplifier(s).

b. Gradually decrease the voltage of the detector bias power supply to zero and turn the power supply off.

c. Turn off the preamplifier power supply.

d. Reattach the alignment mirror to the APD TS to protect the collector of the detector.

\section{APD TS Equipment}

a. APD detector bias power supply, Bertan Assoc. Inc., Model $602 B-15 P$.

b. Precision digital voltmeter for detector bias voltage measurement.

c. CLC100 linear amplifiers, Comlinear Corporation. 
d. Oscilloscope readout, Tektronix 7904, NIST 145935 (used at NIST).

1. APD readout, dual trace amplifier, 7A24, $50 \Omega$.

2. Dual time base, 7B92A.

e. Preamplifier bias power supply (NIST made).

f. Temperature controller power supply (NIST made).

g. Low-pass filter, $3 \mathrm{~dB}$ cutoff frequency $30 \mathrm{MHz}$, Gaussian roll-off; Reactel, Inc., Model 7LX4-30-B21.

\section{Calibration Procedures}

a. Responsivity.

Procedures for calibrating responsivity have been described in several publications [1-4], and are briefly reviewed here. An acousto-optically modulated $\mathrm{cw} 1.064 \mu \mathrm{m}$ laser beam in the TEM o $_{\text {o }}$ mode generates alternately equal levels of pulsed power and cw power into a low-level beam splitter. The cw power measured by a transfer standard in the transmitted beam of the splitter is used to determine the pulsed power into the APD transfer standard in one of the reflected beams of the splitter. The calibration factor is found by dividing the peak output voltage by the pulsed power per aperture area of the APD collector.

b. Impulse response related corrections of the peak voltage of the APD transfer standards.

A transient digitizer recorded the impulse responses of the APD transfer standards. These data were read into computer programs that convolved the unit-area impulse response with unit-height Gaussian pulses of various selected durations. From these data, correction factors of the pulse peak for observed pulse durations from 10 to 100 ns were determined. 
Inserting a $30 \mathrm{MHz}$ filter in the detector system reduces noise and increases sensitivity. However, the correction factor for the peak voltage and its uncertainty also increase, especially for the shorter pulses. See correction factor curves, figures 2 through 13.

Use the following measurements and equations to calibrate directly the correction factor for the peak voltage with the $40 \mathrm{~dB}$ amplifier and $30 \mathrm{MHz}$ filter: (1) Measure peak power near the bottom of the range with the $20 \mathrm{~dB}$ amplifier and no filter and (2) Determine the correction factor for the peak voltage with the peak power unchanged and near the top of the range with the $40 \mathrm{~dB}$ amplifier and the $30 \mathrm{MHz}$ filter.

Apply the following equations:

$$
\mathrm{W}_{\mathrm{p}}=\frac{\mathrm{CF}_{20} \mathrm{~V}_{\mathrm{p} 20}}{\mathrm{~K}_{20}}
$$

near the bottom of the range with the $20 \mathrm{~dB}$ amplifier and no filter where

$$
\begin{aligned}
& \mathrm{W}_{\mathrm{p}}=\text { peak power in watts } \\
& \mathrm{CF}_{20}=\begin{array}{l}
\text { correction factor of peak voltage with } 20 \mathrm{~dB} \text { amplifier } \\
(\text { see figs. } 2-13)
\end{array} \\
& \mathrm{V}_{\mathrm{p} 20}=\text { peak voltage reading with } 20 \mathrm{~dB} \text { amplifier } \\
& \mathrm{K}_{20}=\text { calibration factor with } 20 \mathrm{~dB} \text { amplifier (see tables } 1,2, \\
& \text { or } 3 \text {, column } 1 \text { ); }
\end{aligned}
$$

and

$$
\mathrm{W}_{\mathrm{p}}=\frac{\mathrm{CF}_{40 \mathrm{~F}} \mathrm{~V}_{\mathrm{p} 40 \mathrm{~F}}}{\mathrm{~K}_{40 \mathrm{~F}}}
$$


near the top of the range with the $40 \mathrm{~dB}$ amplifier and the filter where

$$
\mathrm{W}_{\mathrm{p}}=\text { peak power, as before }
$$

$$
\begin{aligned}
\mathrm{CF}_{4 \mathrm{OF}}= & \text { correction factor of peak voltage with } 40 \mathrm{~dB} \text { amplifier } \\
& \text { and } 30 \mathrm{MHz} \text { filter (to be calculated) }
\end{aligned}
$$

$\mathrm{K}_{40 \mathrm{~F}}=$ calibration factor with $40 \mathrm{~dB}$ amplifier and $30 \mathrm{MHz}$ filter (see tables 1, 2, or 3, column 1)

$\mathrm{V}_{\mathrm{p} 40 \mathrm{~F}}=$ peak voltage with $40 \mathrm{~dB}$ amplifier and $30 \mathrm{MHz}$ filter corresponding to an observed pulse duration.

From these equations we get the correction factor

$$
C F_{40 F}=\frac{W_{p} K_{40 F}}{V_{p 40 F}}
$$

If the laser pulse maintains its shape, then $\mathrm{CF}_{40 \mathrm{~F}}$ is constant over the range of the detector with $40 \mathrm{~dB}$ amplifier and $30 \mathrm{MHz}$ filter.

Curves of correction factor of peak voltage versus observed pulse duration for identical gain and measurement parameters are very repeatable. However, correction factors at the highest peak power range $(0 \mathrm{~dB})$ differ for changes in level of the Gaussian impulse response. These differences diminish rapidly with increased pulse duration. See tables 5, 6, and 7. They are due to load differences when changing gain settings of the transient digitizer, during impulse response measurements.

For a given gain and set of measurement parameters of APD 721, the convolution of the impulse response with Gaussian, skewed Gaussian, and cosine-squared input pulses at a given observed pulse duration 
yield approximately the same correction factors of the peak voltage. See tables 8 through 11. Convolution with triangular and rectangular (not shown) input pulses yield more scattered correction factors of the peak voltage from the above.

\section{Acknowledgments}

The authors thank J.J. Skudler for designing and fabricating transfer standard components. They also thank the Aerospace Guidance and Metrology Center, Newark Air Force Station for funding this work.

\section{References}

[1] Sanders, A. A.; Rasmussen, A. L. A system for measuring energy and peak power of low-level $1.064 \mu \mathrm{m}$ laser pulses. NBS Tech. Note 1058 (1982).

[2] Rasmussen, A. L.; Sanders, A. A. Transfer standards for energy and peak power of low-level 1.064 micrometer pulses and continuous wave laser power. Optical Engineering 25(2), 277-285; 1986 February.

[3] Rasmussen, A. L.; Sanders, A. A. Documentation of the NBS APD and PIN calibration systems for measuring peak power and energy of lowlevel $1.064 \mu \mathrm{m}$ laser pulses. NBSIR 85-3032, 1985 December.

[4] Rasmussen, A. L.; Franzen, D. L. Low-level germanium detector transfer standard at $1.064 \mu \mathrm{m}$. NBSIR 85-3041, 1986 January. 


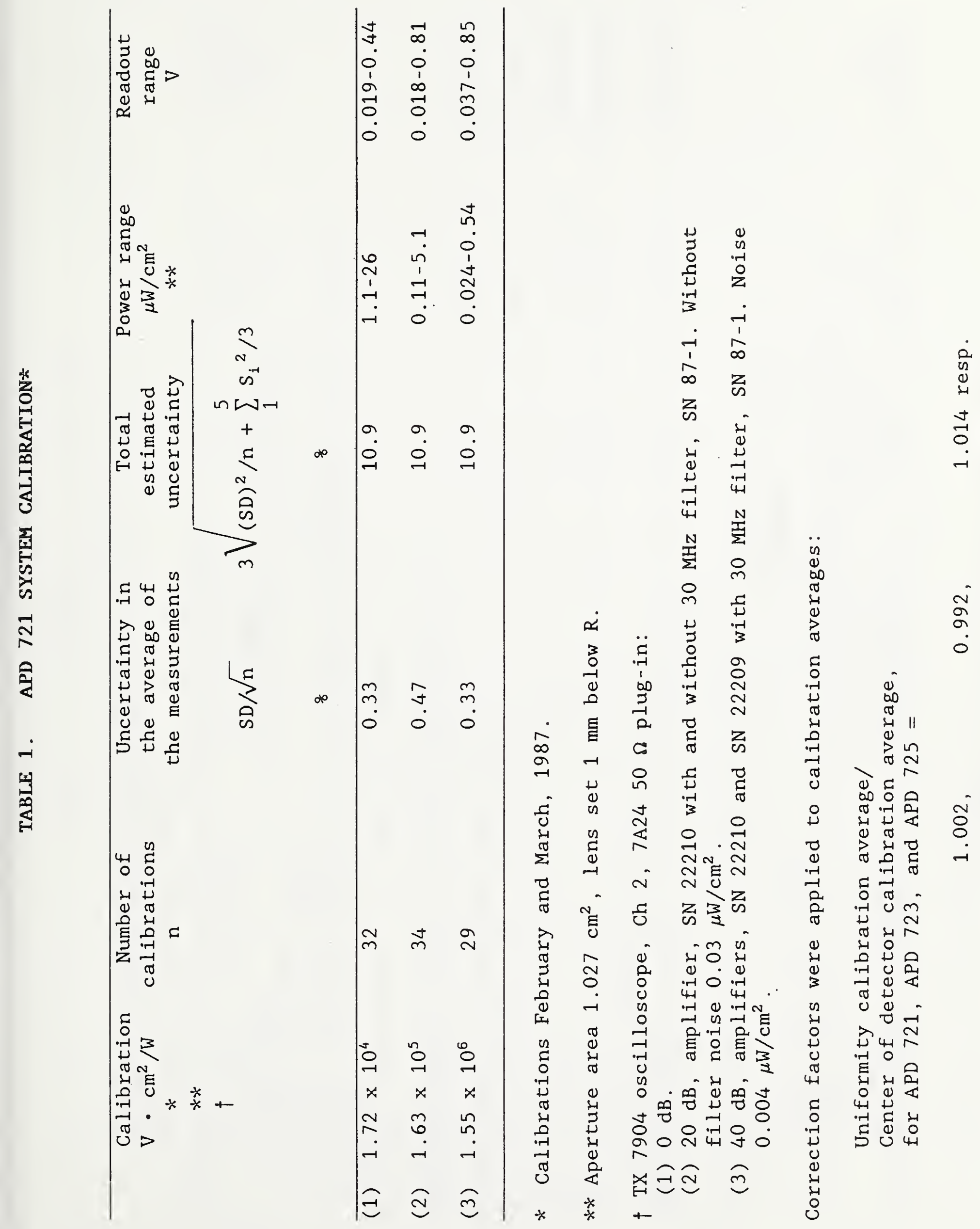




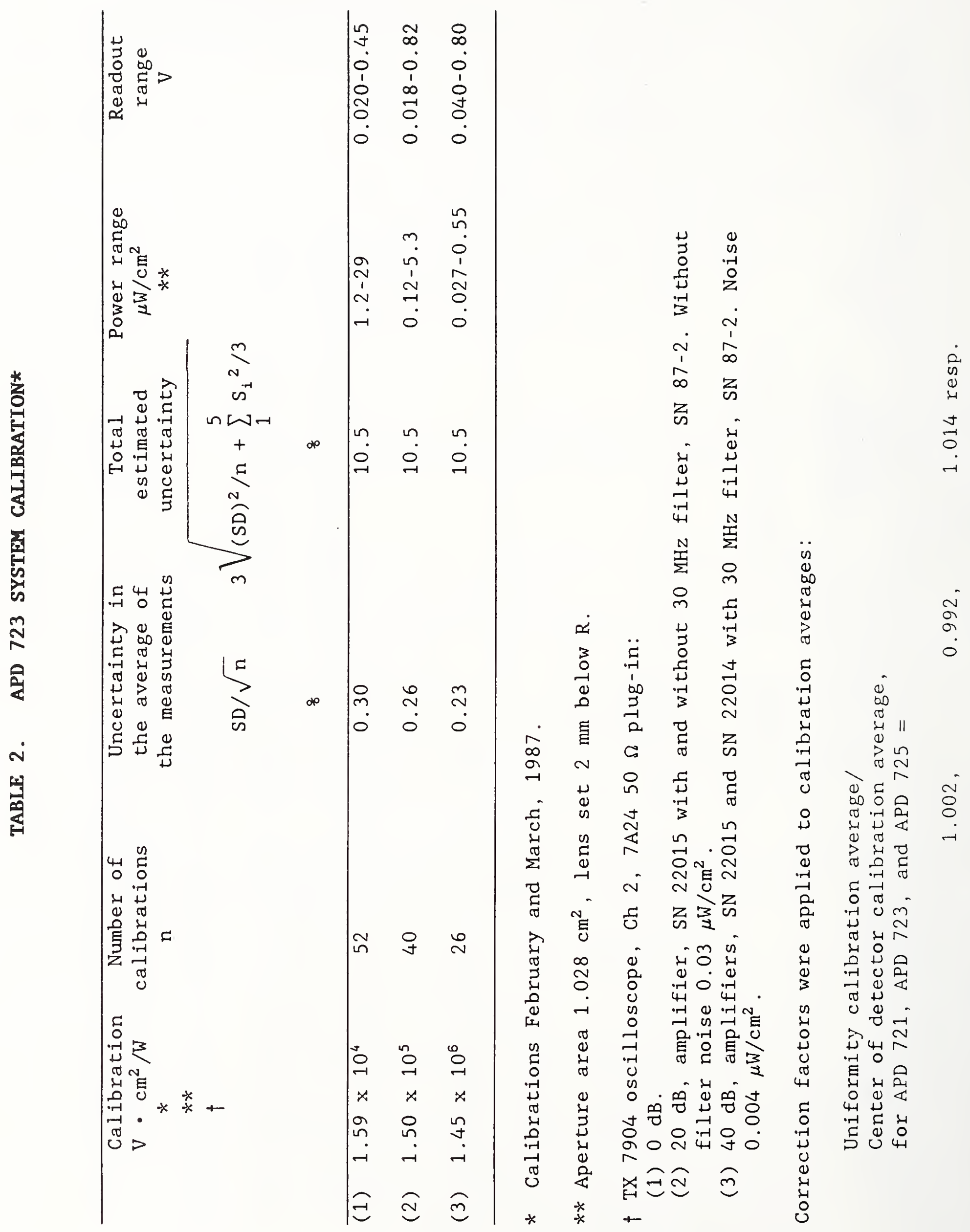




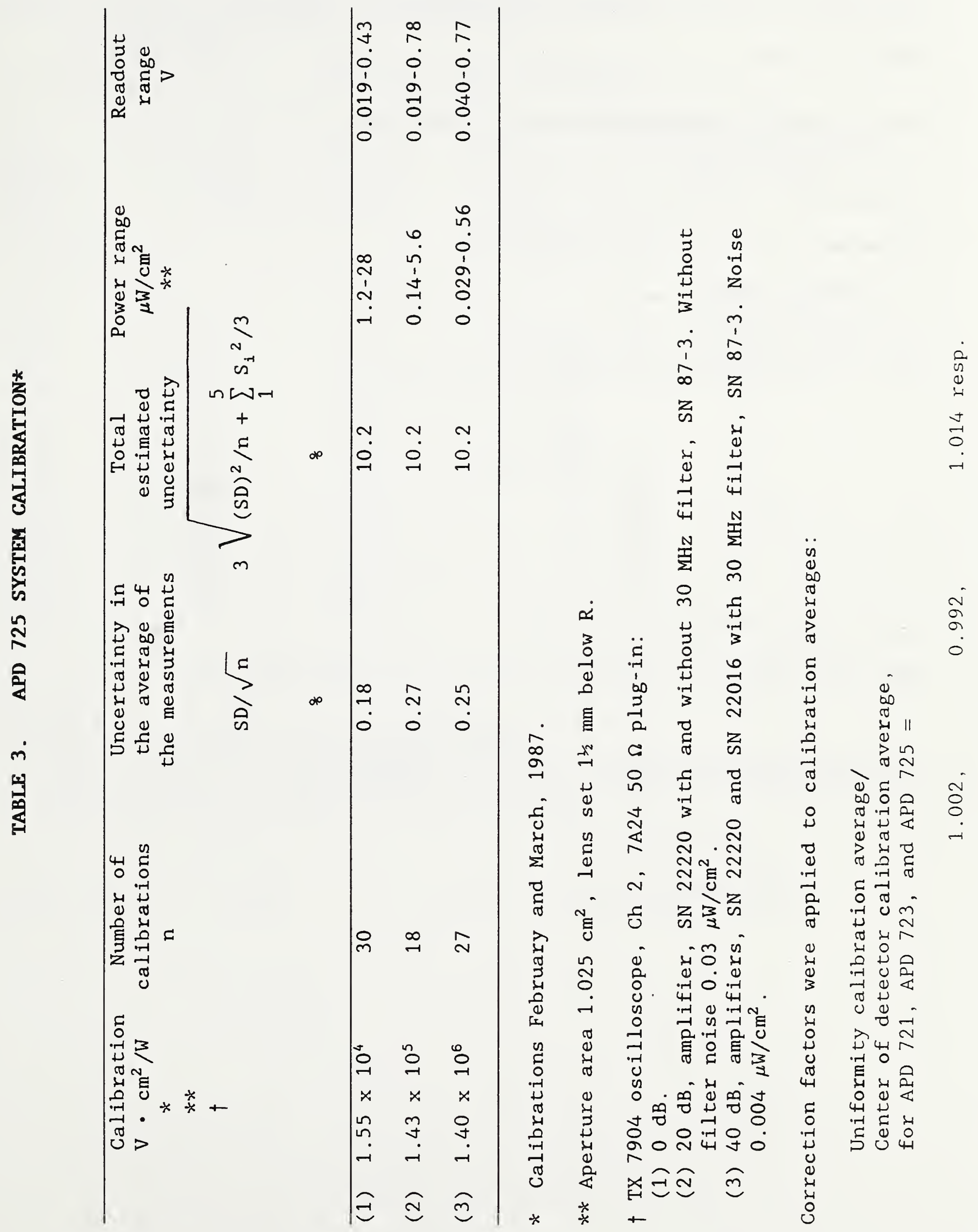


TABLE 4. Error budget APD 721, APD 723, and APD 725 system.

Source of error

Uncertainty 8

Redw 3 transfer standard(identifying designation

to commercial instrument), $\mathrm{S}_{1}$

1.9

Beamsplitter attenuator, $\mathrm{S}_{2}$

2.5

Equivalence of pulsed and $\mathrm{cw}$ power, $\mathrm{S}_{3}$

Oscilloscope readout, $\mathrm{S}_{4}$

3.0

Correction factor of peak voltage for

OBS $\Delta t$ (observed pulse duration) $\geq 15 \mathrm{~ns}, \mathrm{~S}_{5}$

$$
\sqrt{\sum_{1}^{5} S_{i}^{2} / 3}
$$

Precision and uniformity, (SD) $/ \sqrt{\mathrm{n}}$ :

$(\mathrm{SD})_{1} / \sqrt{\mathrm{n}_{1}}(\mathrm{APD} 721),(\mathrm{SD})_{2} / \sqrt{\mathrm{n}_{2}}(\mathrm{APD} 723)$, and $(\mathrm{SD})_{3} / \sqrt{\mathrm{n}_{3}}(\mathrm{APD} 725)=$
1.38
0.88
0.37 resp.

Total uncertainty for APD 721, APD 723, and APD 725:

$$
3 \sqrt{(S D)^{2} / n+\sum_{1}^{5} s_{i}^{2} / 3}=10.9
$$

10.5,

10.2 resp. 
TABLE 5. Percent deviation of average CF $V_{p}$ from CF $V_{p}$ data of individual runs (see Fig. 2)

\section{APD $721-0 \mathrm{~dB}-$ No Filter}

\begin{tabular}{|c|c|c|c|c|}
\hline $\begin{array}{l}\text { Input } \\
\text { Gaussian } \\
\text { pulse } \\
\text { duration } \\
\text { ns }\end{array}$ & $\begin{array}{l}\text { Average } \\
C F V_{p}^{*} \dagger \\
\text { of runs } \\
9 \& 10\end{array}$ & $\begin{array}{l}\text { Average } \\
\text { OBS } \Delta t^{* *} \dagger \\
\text { of runs } \\
9 \& 10\end{array}$ & $\begin{array}{l}\text { Percent } \\
\text { deviation of } \\
\text { average CF } V_{p}{ }^{*} \\
\text { from CF } V_{p} \\
\text { of runs } 9^{*} 10\end{array}$ & $\begin{array}{l}\text { Impulse response } \\
\text { peak voltage }\end{array}$ \\
\hline
\end{tabular}

$\begin{array}{rrrrr}10 & 0.961 & 9.6 & \pm 1.4 & \text { Run 9, 203 mV } \\ 15 & 0.987 & 14.6 & 0.8 & \text { Run 10, } 20.1 \mathrm{mV} \\ 20 & 0.999 & 19.7 & 0.4 & \\ 25 & 1.005 & 24.8 & 0.2 & \\ 30 & 1.007 & 29.9 & 0.1 & \\ 35 & 1.008 & 35.0 & 0.1 & \\ 40 & 1.009 & 40.1 & 0 & \\ 50 & 1.008 & 50.3 & 0 & \\ 60 & 1.007 & 60.3 & 0 & \\ 70 & 1.006 & 70.3 & 0 & \\ 80 & 1.005 & 80.3 & 0 & \\ 90 & 1.004 & 90.3 & 0 & \\ 100 & 1.003 & 100.3 & & \end{array}$

* $\quad C F V_{p}=$ correction factor peak voltage

* OBS $\Delta t=$ observed pulse duration

$\dagger$ Correcting the impulse response for transient digitizer calibration yielded identical values of $C F V_{p}$ and $O B S \Delta t$. 
TABLE 6. Percent deviation of average CF $V_{p}$ "from CF $V_{p}$ data of individual runs (see Fig. 6)

\section{APD $723-0 \mathrm{~dB}$ - No Filter}

\begin{tabular}{|c|c|c|c|c|}
\hline $\begin{array}{l}\text { Input } \\
\text { Gaussian } \\
\text { pulse } \\
\text { duration } \\
\quad \text { ns }\end{array}$ & $\begin{array}{l}\text { Average } \\
C F \quad V_{p}{ }^{t} \dagger \\
\text { of runs } \\
16 \& 17\end{array}$ & $\begin{array}{l}\text { Average } \\
\text { OBS } \Delta t^{* *} \dagger \\
\text { of runs } \\
16 \& 17\end{array}$ & $\begin{array}{l}\text { Percent } \\
\text { deviation of } \\
\text { average } C F \quad V_{p}{ }^{*} \\
\text { from } C F V_{p} \\
\text { of runs } 16 \& 17\end{array}$ & $\begin{array}{l}\text { Impulse response } \\
\text { peak voltage }\end{array}$ \\
\hline
\end{tabular}

\begin{tabular}{rrrrl}
\hline 10 & 0.964 & 9.74 & \pm 3.2 & Run 16, 20.9 mV \\
15 & 0.982 & 14.6 & 2.3 & Run 17, 206 mV \\
20 & 0.994 & 19.7 & 1.7 & \\
25 & 0.999 & 24.7 & 1.4 & \\
30 & 1.002 & 29.8 & 1.2 & \\
35 & 1.004 & 34.9 & 1.0 & \\
40 & 1.005 & 40.0 & 0.9 & \\
50 & 1.005 & 50.1 & 0.7 & \\
60 & 1.004 & 60.2 & 0.6 & \\
70 & 1.004 & 70.2 & 0.4 & \\
80 & 1.003 & 80.2 & 0.4 & \\
90 & 1.002 & 90.2 & 0.3 & \\
100 & 1.002 & 100.2 & 0.2 &
\end{tabular}

CF $V_{p}=$ correction factor peak voltage

OBS $\Delta t=$ observed pulse duration

Correcting the impulse response for transient digitizer calibration yielded identical values of $C F V_{p}$ and OBS $\Delta t$. 
TABLE 7. Percent deviation of average CF $V_{p}{ }^{*}$ from CF $V_{p}$ data of individual runs ( see Fig. 10)

$$
\text { APD } 725 \text { - } 0 \text { dB - No Filter }
$$

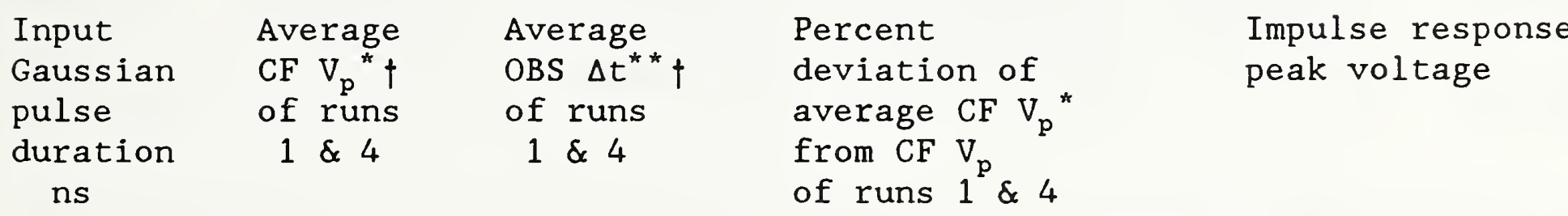

$\begin{array}{rrrrr}10 & 0.962 & 9.72 & \pm 2.2 & \text { Run } 1,204 \mathrm{mV} \\ 15 & 0.980 & 14.7 & 1.5 & \text { Run } 4,19.7 \mathrm{mV} \\ 20 & 0.990 & 19.7 & 1.2 & \\ 25 & 0.995 & 24.8 & 0.9 & \\ 30 & 0.998 & 29.8 & 0.8 & \\ 35 & 0.999 & 34.9 & 0.7 & \\ 40 & 1.000 & 39.9 & 0.7 & \\ 50 & 1.001 & 50.0 & 0.5 & \\ 60 & 1.001 & 60.0 & 0.4 & \\ 70 & 1.001 & 70.0 & 0.3 & \\ 80 & 1.001 & 80.1 & 0.3 & \\ 90 & 1.001 & 90.1 & 0.2 & \\ 100 & 1.001 & 100.1 & 0.2 & \end{array}$

$\mathrm{CF} \mathrm{V}_{\mathrm{p}}=$ correction factor peak voltage

OBS $\Delta t=$ observed pulse duration

Correcting the impulse response for transient digitizer calibration yielded identical values of $C F V_{p}$ and $O B S \Delta t$. 
TABLE 8. CF $V_{p}$ as a function of observed pulse duration (OBS $\Delta t$ ) and input pulse shape (Table derived from interpolation of graphed data)

\section{APD 721 - 0 dB - No Filter - Run 10}

Observed pulse

duration

(OBS $\Delta t$ )
$\mathrm{CF} \mathrm{V}_{\mathrm{p}}{ }^{*}$ Gaussian input pulse
$\mathrm{CF} \mathrm{V}_{\mathrm{p}}{ }^{*}$

Skewed $^{\star *}$

Gaussian

input pulse
CF $\mathrm{V}_{\mathrm{p}}{ }^{*}$

Cosine-

squared

input pulse
CF $\mathrm{V}_{\mathrm{p}}{ }^{*}$

Triangular

input pulse

\begin{tabular}{lllll}
\hline 10 & 0.949 & 0.932 & 0.948 & 1.042 \\
15 & 0.981 & 0.963 & 0.980 & 1.032 \\
20 & 0.996 & 0.985 & 0.997 & 1.028 \\
25 & 1.004 & 0.997 & 1.004 & 1.027 \\
30 & 1.006 & 1.003 & 1.007 & 1.024 \\
35 & 1.008 & 1.006 & 1.01 & 1.023 \\
40 & 1.01 & 1.008 & 1.012 & 1.02 \\
50 & 1.01 & 1.01 & 1.01 & 1.017
\end{tabular}

TABLE 9. $C F V_{p}$ as a function of observed pulse duration (OBS $\Delta t$ ) and input pulse shape (Table derived from interpolation of graphed data)

\section{APD 721 - $20 \mathrm{~dB}$ - No Filter - Run 11}

Observed

pulse

duration

(OBS $\Delta t$ )
$C F V_{p}^{*}$ Gaussian input pulse

\section{CF $\mathrm{V}_{\mathrm{p}}{ }^{*}$}

Skewed $^{*}$ *

Gaussian

input pulse
CF $\mathrm{V}_{\mathrm{p}}$ * Cosinesquared input pulse
CF $V_{p}{ }^{*}$

Triangular

input pulse

$\begin{array}{lllll}10 & 0.921 & 0.914 & 0.921 & 1.022 \\ 15 & 0.958 & 0.943 & 0.962 & 1.006 \\ 20 & 0.973 & 0.963 & 0.972 & 1.010 \\ 25 & 0.982 & 0.975 & 0.986 & 1.007 \\ 30 & 0.988 & 0.982 & 0.989 & 1.006 \\ 35 & 0.992 & 0.987 & 0.994 & 1.006 \\ 40 & 0.994 & 0.990 & 0.994 & 1.005 \\ 50 & 0.996 & 0.994 & 0.997 & 1.004\end{array}$

CF $V_{p}=$ correction factor peak voltage

Skewed Gaussian pulses had a Gaussian right side with a FWHM $40 \%$ longer than a Gaussian left side. 
TABLE 10. $C F V_{p}$ as a function of observed pulse duration (OBS $\Delta t$ ) and input pulse shape (Table derived from interpolation of graphed data)

APD $721-20 \mathrm{~dB}-$ Filter - Run 12

$\begin{array}{lllll} & C F v_{p}{ }^{*} & C F v_{p}{ }^{*} & C F v_{p}{ }^{*} & C F v_{p}{ }^{*} \\ \text { Observed } & \text { Gaussian } & \text { Skewed } & \text { Cosine- } & \text { Triangular } \\ \text { pulse } & \text { input } & \text { Gaussian } & \text { squared } & \text { input pulse } \\ \text { duration } & \text { pulse } & \text { input pulse } & \text { input pulse } & \\ (\text { OBS } \Delta t) & & & \end{array}$

\begin{tabular}{lllll}
\hline 16 & 1.418 & 1.427 & 1.373 & 1.524 \\
20 & 1.178 & 1.193 & 1.147 & 1.279 \\
25 & 1.091 & 1.090 & 1.067 & 1.182 \\
30 & 1.055 & 1.051 & 1.039 & 1.143 \\
35 & 1.033 & 1.033 & 1.029 & 1.122 \\
40 & 1.022 & 1.023 & 1.022 & 1.103 \\
50 & 1.008 & 1.010 & 1.008 & 1.070
\end{tabular}

TABLE 11. $C F V_{p}$ as a function of observed pulse duration (OBS $\Delta t$ ) and input pulse shape (Table derived from interpolation of graphed data)

APD $721-40 \mathrm{~dB}-$ Filter - Run 13

$\begin{array}{lllll} & C F v_{p}{ }^{*} & C F v_{p}{ }^{*} & C F V_{p}{ }^{*} & C F v_{p}{ }^{*} \\ \text { Observed } & \text { Gaussian } & \text { Skewed }{ }^{*} & \text { Cosine- } & \text { Triangular } \\ \text { pulse } & \text { input } & \text { Gaussian } & \text { squared } & \text { input pulse } \\ \text { duration } & \text { pulse } & \text { input pulse } & \text { input pulse } & \\ \text { (OBS } \Delta t) & & & \end{array}$

\begin{tabular}{llcll}
\hline 16 & 1.462 & - & 1.428 & 1.550 \\
20 & 1.153 & 1.170 & 1.121 & 1.248 \\
25 & 1.050 & 1.050 & 1.032 & 1.149 \\
30 & 1.019 & 1.014 & 1.004 & 1.108 \\
35 & 1.003 & 0.998 & 0.994 & 1.087 \\
40 & 0.995 & 0.992 & 0.992 & 1.073 \\
50 & 0.987 & 0.985 & 0.986 & 1.052
\end{tabular}

* CF $V_{p}=$ correction factor peak voltage

* *kewed Gaussian pulses had a Gaussian right side with a FWHM $40 \%$ longer than a Gaussian left side. 


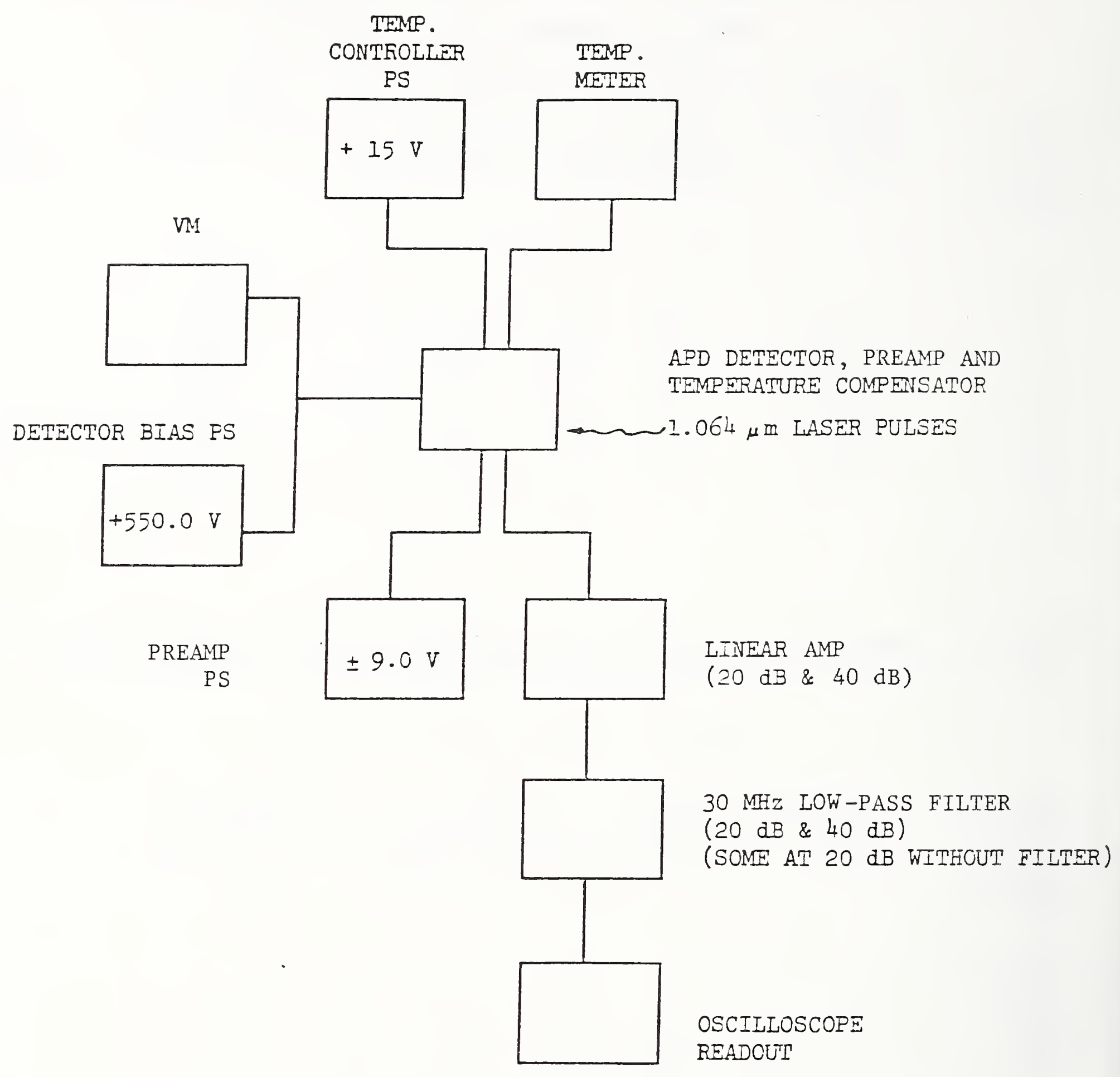

Figure 1. APD Transfer Standard System 


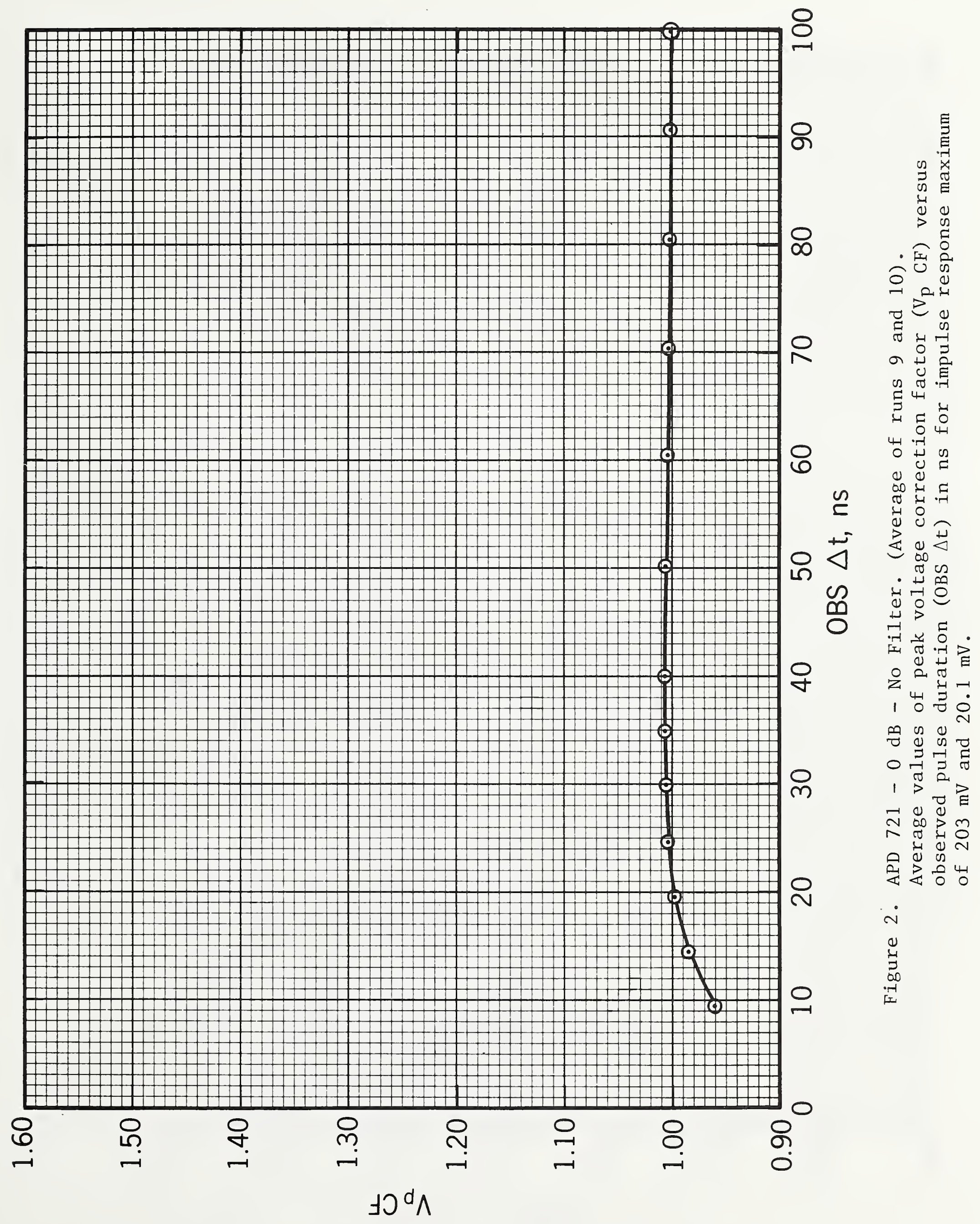




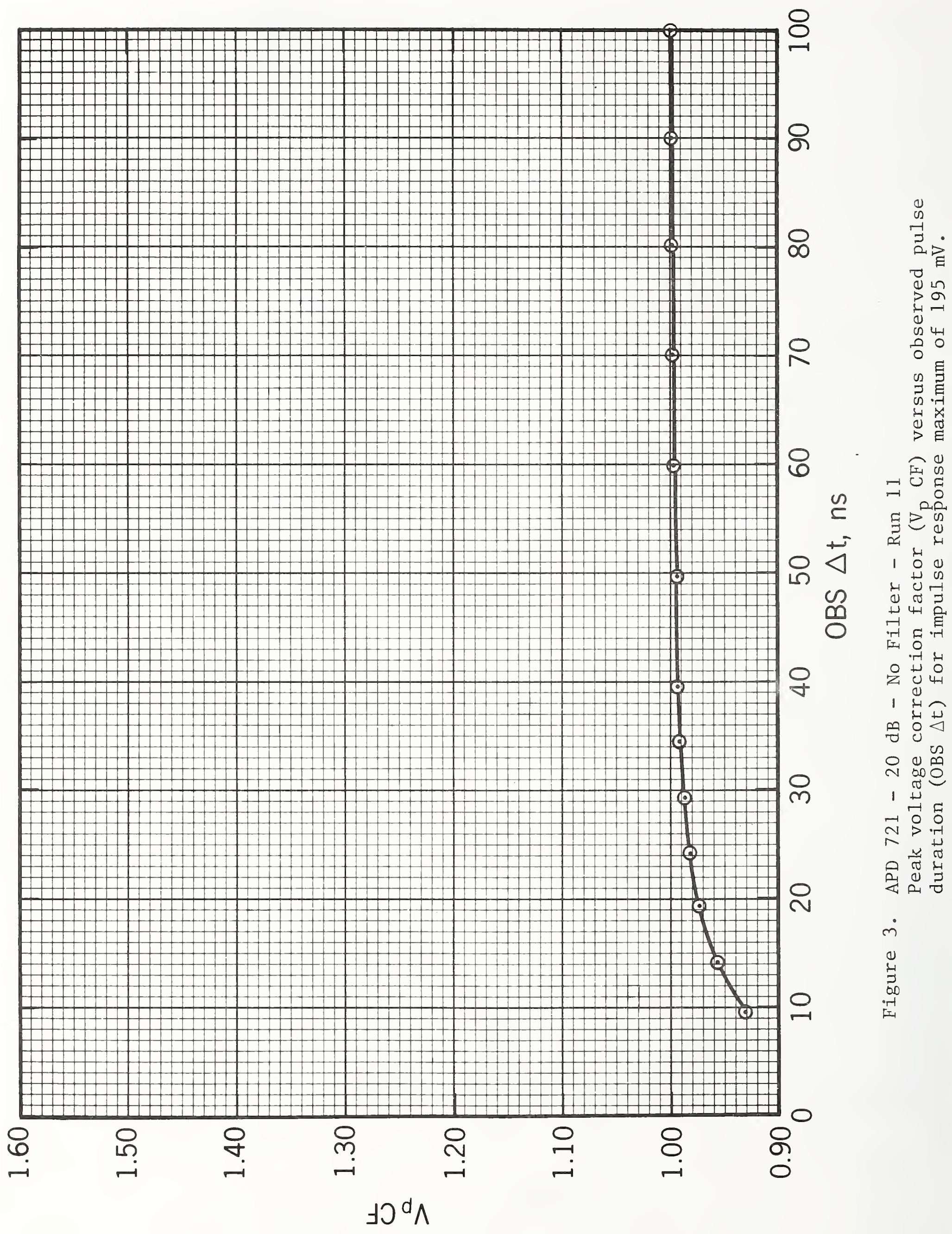




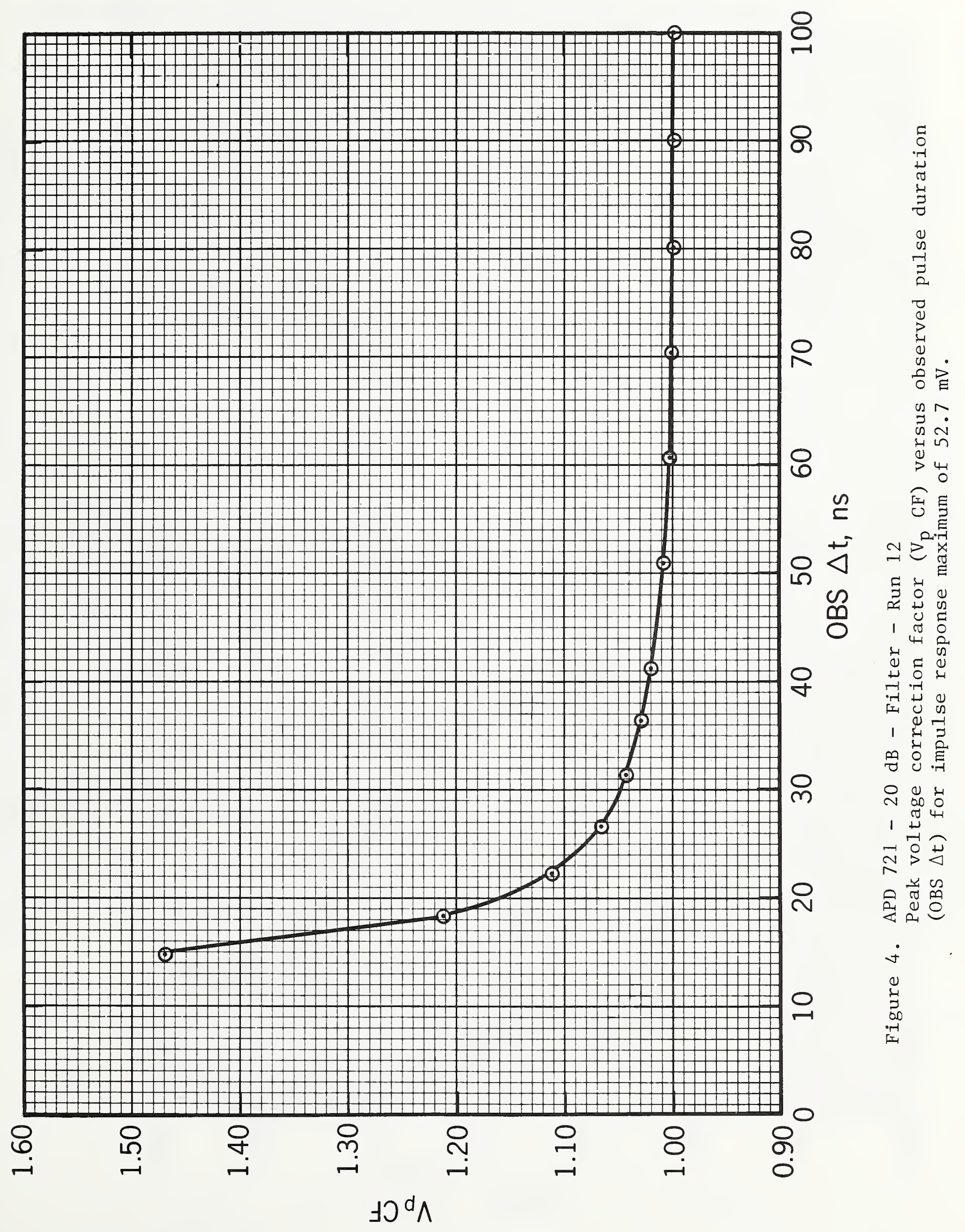




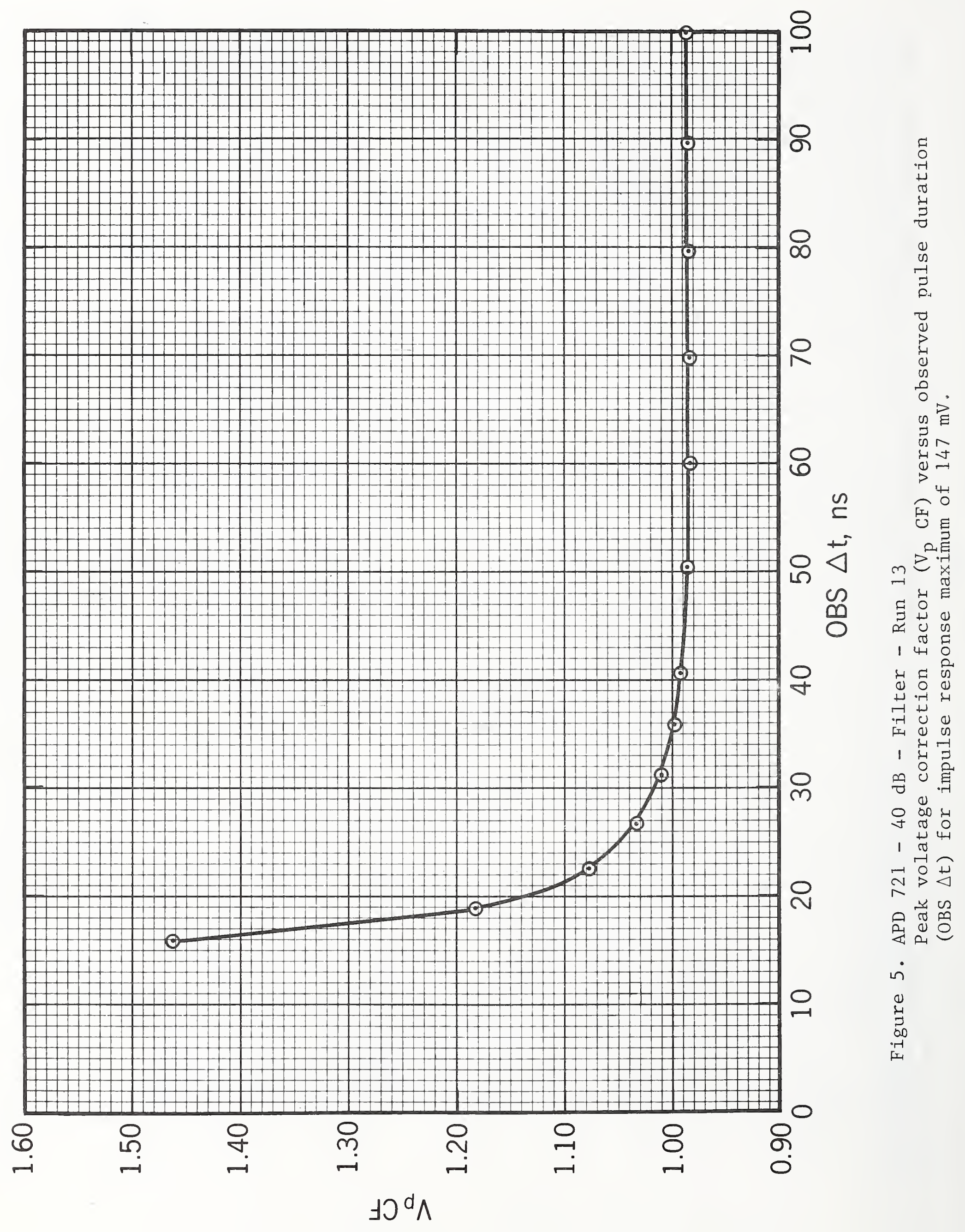




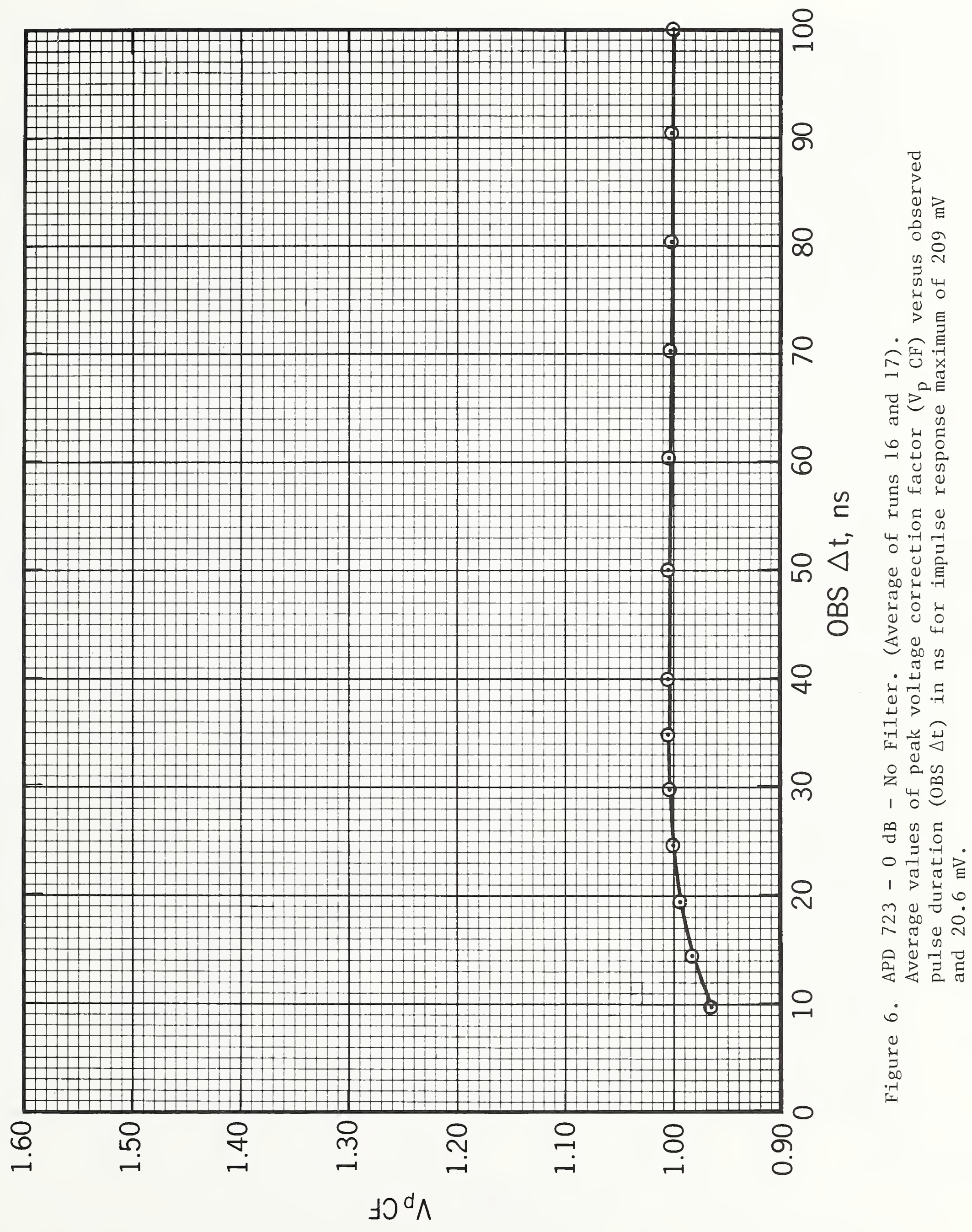




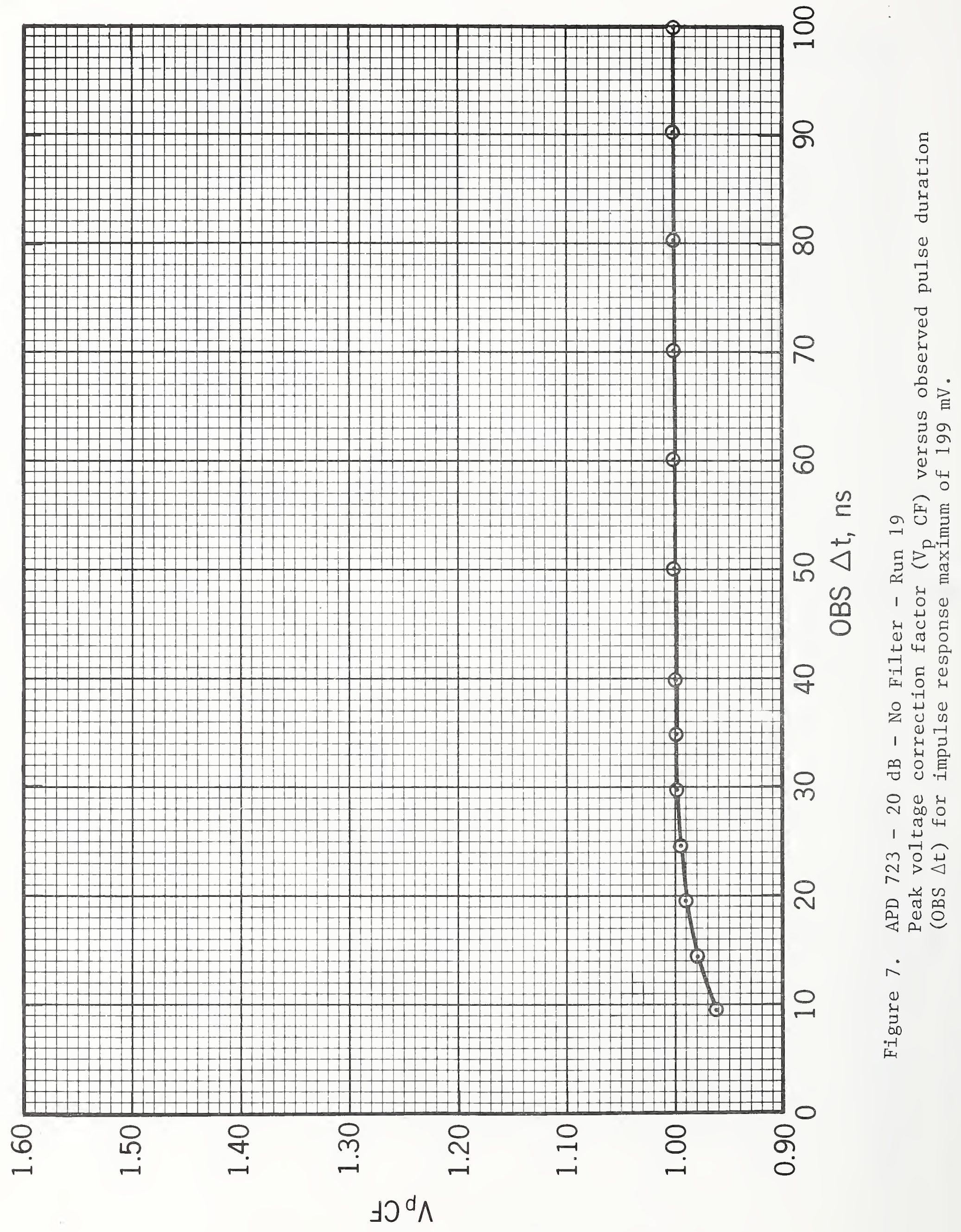




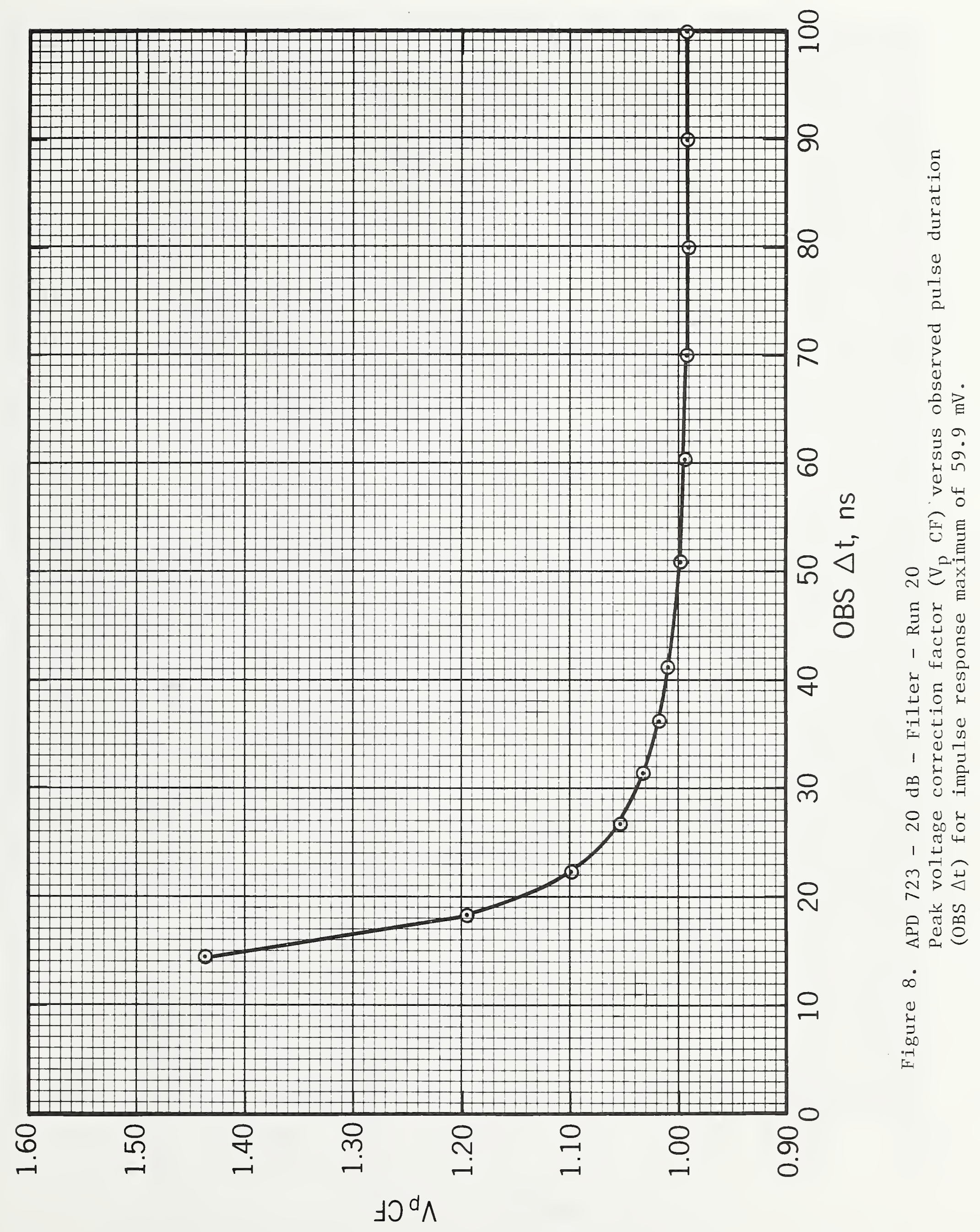




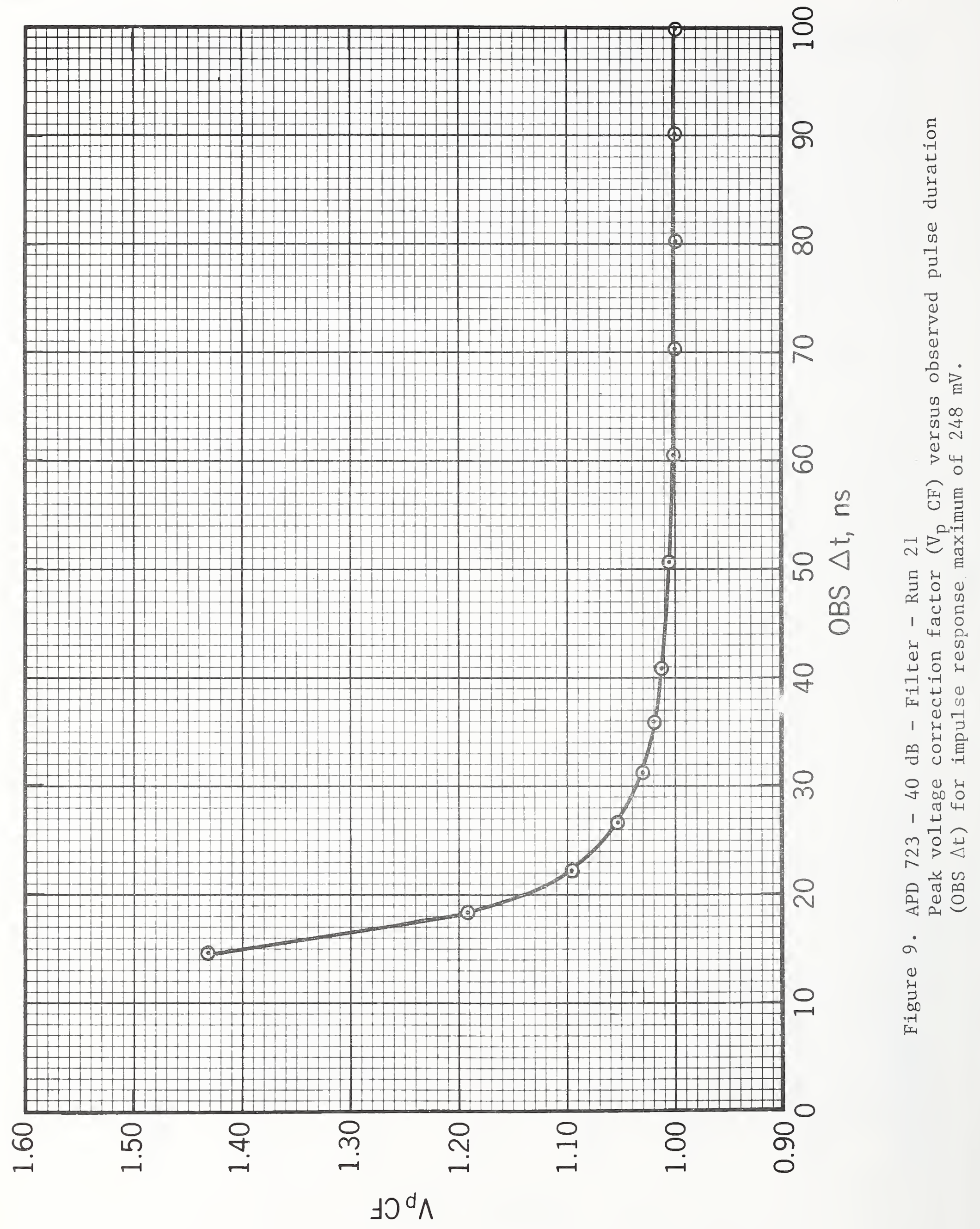




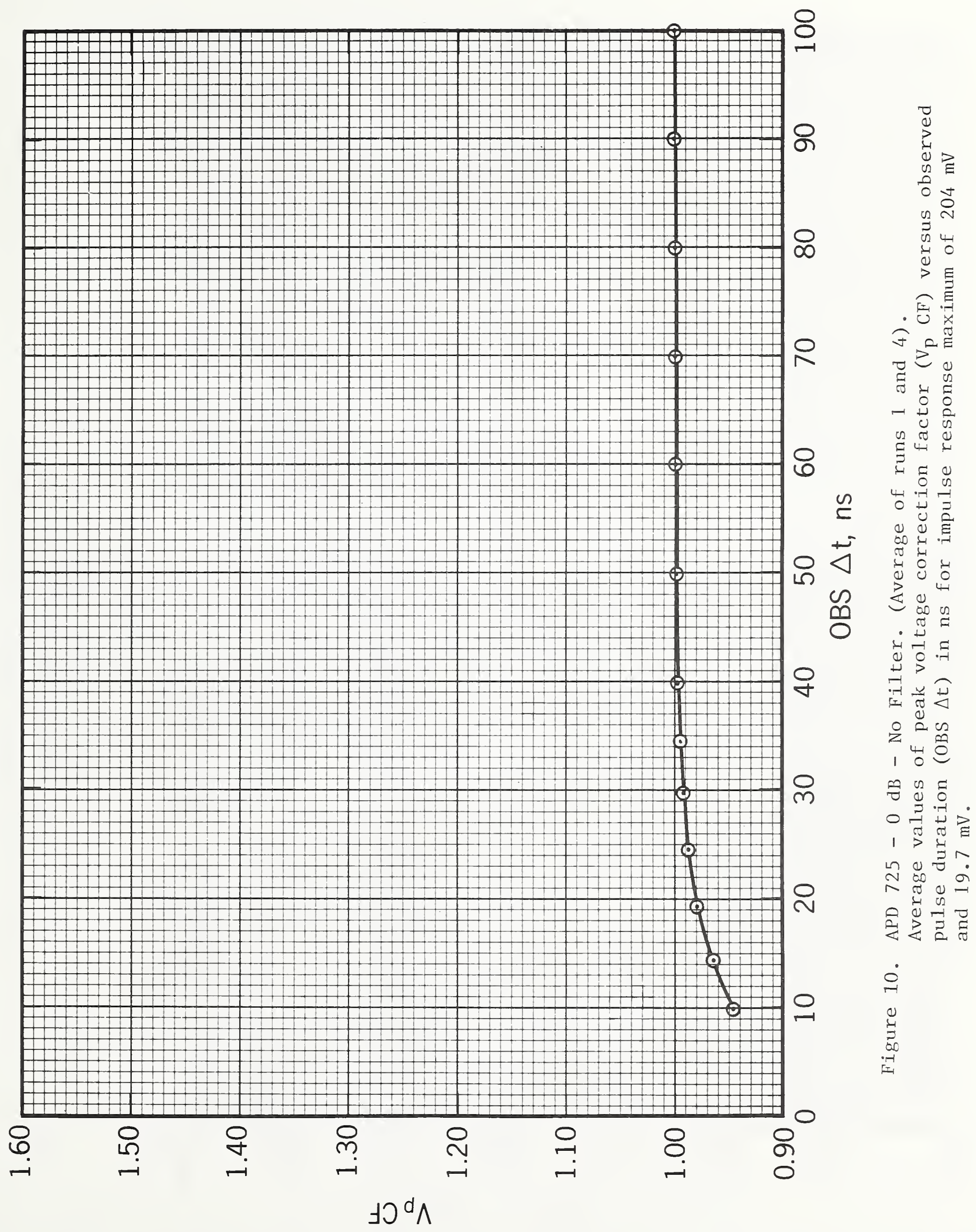




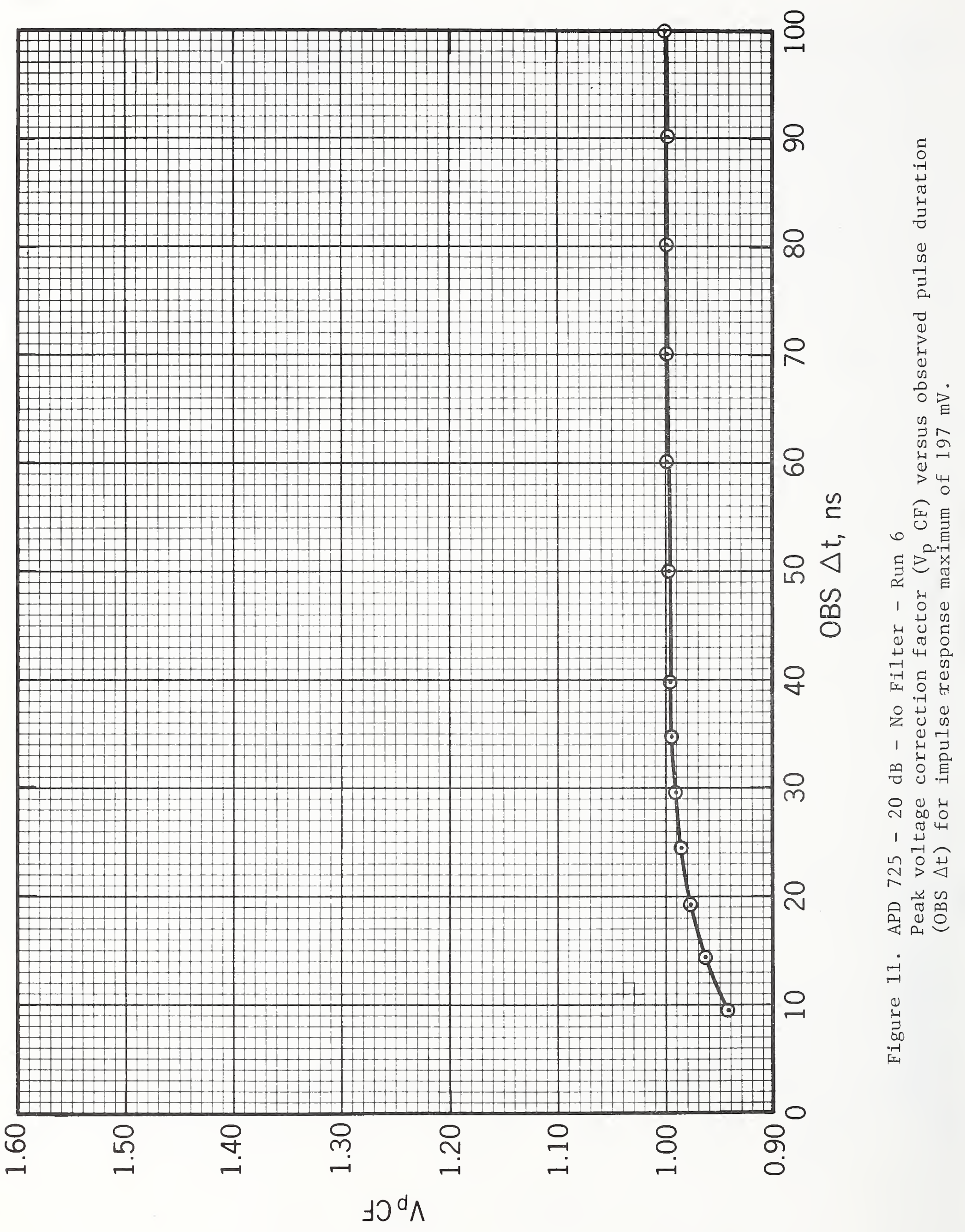




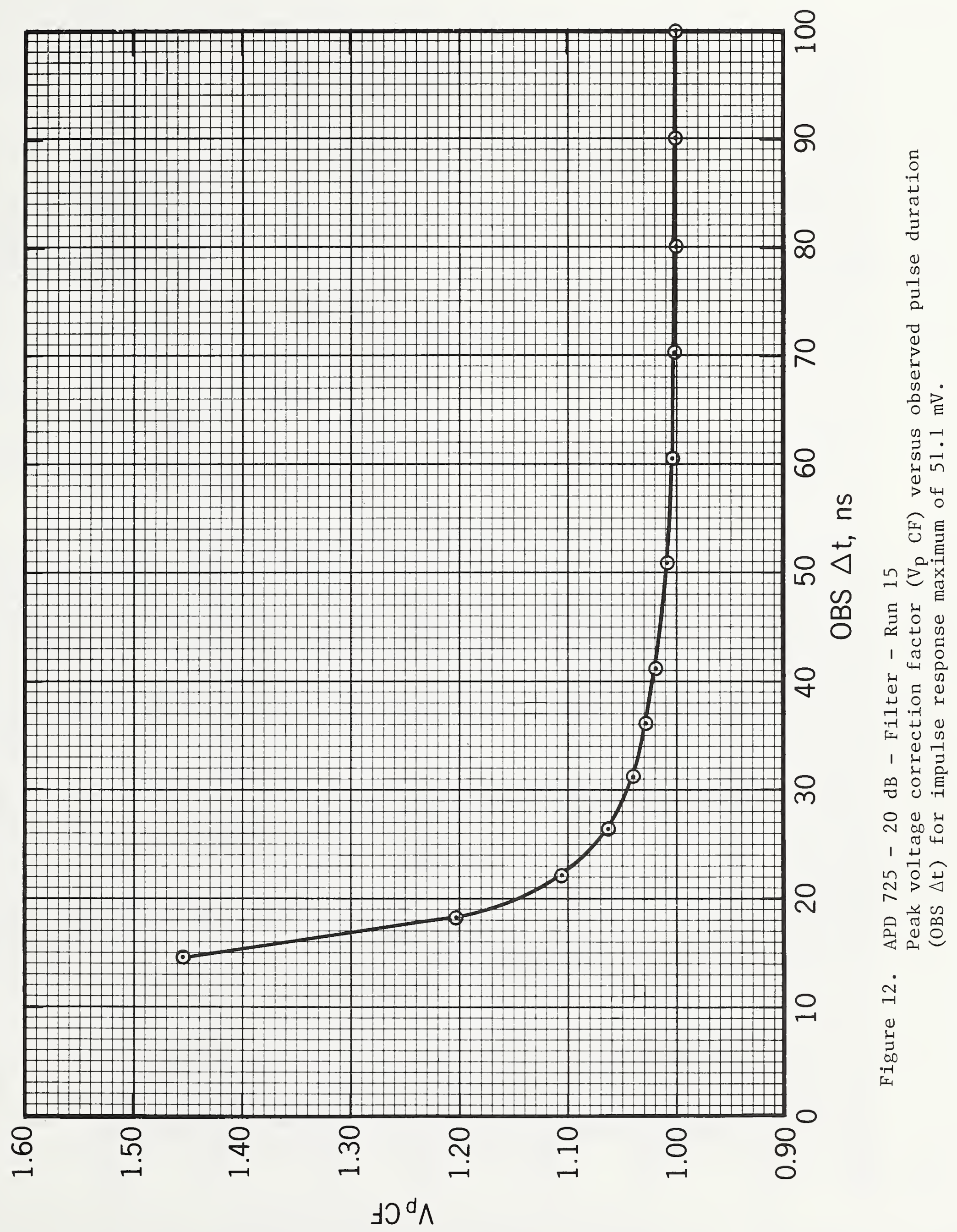




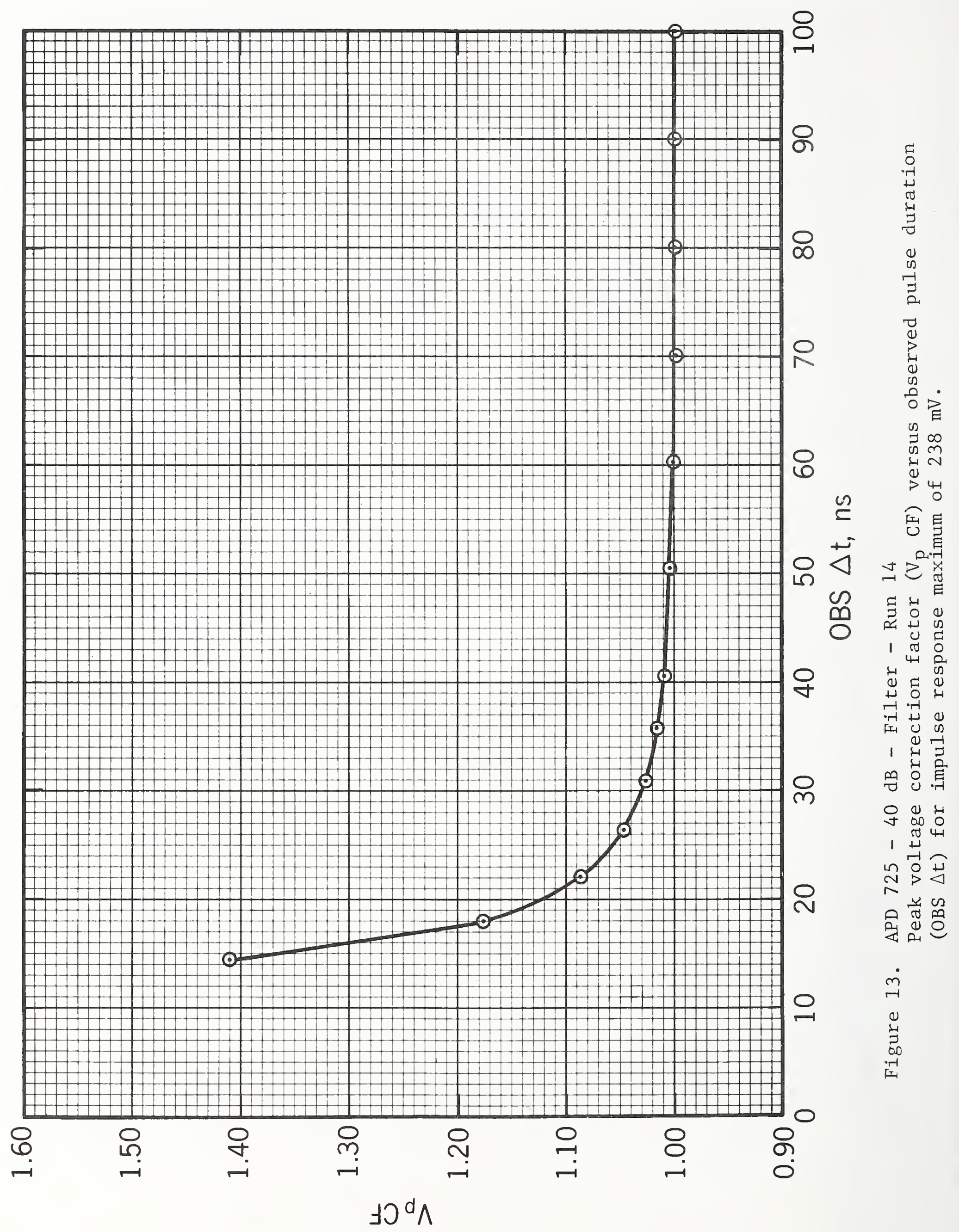


NBS-114A (REV. 2-8C)

U.S. DEPT. OF COMM.

BIBLIOGRAPHIC DATA

SHEET (See instructions)

1. PUBLICATION OR REPORT NO.

NISTIR 89-3917
2. Performing Organ. Report No.

3. Publication Date

August 1989

4. TITLE AND SUBTITLE

Improved Low-Level Silicon-Avalanche-Photodiode Transfer Standards at 1.064 Micrometers.

5. $A \cup T H O R(S)$

A.L. Rasmussen, P.A. Simpson, and A.A. Sanders

6. PERFORMING ORGANIZATION (If joint or other than NBS, see instructions) National Institute of Standards and Technology

AATFOTFE

DEPARTMENT OF COMMERCE

WASHINGTON, D.C. 20234

7. Contract/Grant No.

8. Type of Report \& Period Covered

9. SPONSORING ORGANIZATION NAME AND COMPLETE ADDRESS (Street. City, State, ZIP)

Aerospace Guidance and Metrology Center

Newark Air Force Station, Ohio

10. SUPPLEMENTARY NOTES

Document describes a computer program; SF-185, FIPS Software Summary, is attached.

11. ABSTRACT (A 200-word or less factual summary of most significant information. If document includes a significant

bibliography or literature survey, mention it here)

Three silicon-avalanche-photodiode (APD) transfer standards were calibrated from $\sim 10^{-8}$ to $-10^{-5} \mathrm{~W} / \mathrm{cm}^{2}$ peak power density at approximately 108 uncertainty. These calibrations are for $1.064 \mu \mathrm{m}$ wavelength pulses of 10 to $100 \mathrm{~ns}$ duration. For this calibration, an acousto-optically modulated laser beam generated alternately equal levels of pulsed power and $\mathrm{cw}$ power into a low-level beam splitter. The $\mathrm{cw}$ power measured by a transfer standard in the transmitted beam of the splitter was used to determine the pulsed power into the APD transfer standard in one of the low-level reflected beams of the splitter. The APD detector had about a $1 \mathrm{~cm}^{2}$ aperture and a $3.8 \mathrm{~cm}$ focal length lens in front of it. Lens, window, and detector surfaces had narrow-band antireflection coatings. The commercial detector package is a temperature compensated, infrared-enhanced APD preamplifier module. To increase the sensitivity, one or two $20 \mathrm{~dB}, 500 \mathrm{MHz}$ bandwidth amplifiers followed the preamplifier. With very low pulsed power, a $30 \mathrm{MHz}$ low-pass filter with Gaussian roll-off was attached to the amplifier output to reduce the noise. A transient digitizer recorded the impulse responses of the APD detectors at $1.064 \mu \mathrm{m}$. These data were read into computer programs that convolved the unit-area impulse response with unit-height Gaussian pulses. From these data, correction factors of the pulse peak for observed pulse durations from 10 to 100 ns were determined.

Instructions, calibrations, error budgets, and system descriptions are included.

12. KEY WORDS (Six to twelve entries; alphabetical order: capitalize only proper names; and separate key words ty semicolons) detector impulse response; laser detectors; laser pulse standards; lowlevcl pulse detectors; pulse power measurements; YAG laser pulse calibrations

\section{AVAILABILITY}

[X] Unlimited

$\square$ For Official Distribution. Do Not Release to NTIS

$\square$ Order From Superintendent of Documents, U.S. Government Printing Office, Washington, D.C. 20402.

[X] Order From National Technical Information Service (NTIS), Springfield, VA. 2216।

14. NO. OF PRINTED PAGES

$$
44
$$

15. Price 




